\title{
Electromagnetic Design and Experiment of Halbach Array Based Permanent Magnet Fault-Tolerant Motors
}

\author{
Cheng Ying \\ School of Electrical Engineering \\ Nantong University \\ Nantong, China \\ email:13003535300@163.com \\ Mao Jingfeng* \\ School of Electrical Engineering \\ Nantong University \\ Nantong, China \\ email:mao.jf@ntu.edu.cn
}

\author{
Wu Aihua \\ School of Electrical and Information Engineering \\ Jiangsu University \\ Zhenjiang, China \\ email:wu.ah@ntu.edu.cn \\ Wu Guoqing \\ School of Electrical Engineering \\ Nantong University \\ Nantong, China \\ email:wgq@ntu.edu.cn \\ * Corresponding Author
}

\begin{abstract}
In order to meet high reliability application requirements of modern electric drive system, a kind of Halbach array based permanent magnet fault-tolerant motors (PMFTM) is studied in this paper. Firstly, the structure, characteristics and fault-tolerant working principle of PMFTM are analyzed. Secondly, according to the electromagnetism theorem and Maxwell's equation, the electromagnetic parameters calculation equations are derived, and then the key parameters of $1 \mathrm{KW}$ four-phase six-pole Halbach array based PMFTM are worked out. Thirdly, a PMFTM prototype is built and tested, and the experiment on this researched motor has proved that the rationality and accuracy of this motor.
\end{abstract}

Key words-permanent magnet fault-tolerant motors; Halbach array; motor design; electromagnetic analysis

\section{INTRODUCTION}

With the rapid development of rare earth permanent magnetic materials, permanent magnet motor is getting more and more widely utilization in the electric drive system with its advantages like high efficiency, high torque inertia ratio, high energy density and so on. In some high reliability of electric drive application demand situations, we often use the backup redundancy technology, which connects lots of independent motor systems together in the way of series or parallel, and through switching the working way of hot and cold standby to improve the ability of continuous work of whole machine when machine is at the state of mechanical or electrical parts fault $[1,2]$. This fault-tolerant method has clear principle and simple control, but it still has some weaknesses, like large volume, a lot of parts and low utilization rate. In order to overcome these shortcomings, based on the mind of backup fault-tolerant technology, researching on the permanent magnet motor with high reliability is gradually becoming a hot issue in the study of modern electric drive system[3,4].

Permanent magnet fault-tolerant motor (PMFTM) is a new type of permanent magnet brushless motor which developed in recent years, this kind of motor can also use the phase segregation and redundant capacity method to make the rest of fault phase continue running after one phase or number phases of motor having a failure occurs, in addition to the general advantages of traditional permanent magnet motor. At present, the research of permanent magnet motor on the aspects of motor structure, fault-tolerant control strategy are still in the initial stage. Literature[5,6] respectively used the permanent magnet fault-tolerant motor as the drive motor in electric fuel pump system of electric or overall-electrical plane, and designed them as the electric actuator of electric steering gear system to make the plane has stronger reliability and security. Literature[7] applied permanent magnet fault-tolerant motor into driving system of electric vehicle, and took it as execution motor of wire control steering device to further improve the car driving safety performance. Literature[8] studied the direct torque control and the optimal current control strategy of multiphase permanent magnet fault-tolerant motor. Literature[9] proposed the fault tolerant control strategy with single-phase open circuit which is based on two driving topological structure of H-bridge and star type.

In this paper, a four-phase six-pole permanent magnet fault-tolerant motor is our research target. This motor has combined with the advantages of Halbach permanent magnet array structure in the aspect of sinusoidal in unilateral magnetic field and the aspect of magnetic shielding. According to the analysis of working principle 
of the motor, we determined the phase number, poles number, and the shape of stator slot and rotor magnet steel. Based on the arrangements of rotor magnet steel and the arrangements of winding, and the parameters calculation of magnetic circuit, we obtained the structure parameters of motor with Halbach array, which can make the motor has a small torque ripple and the no-load counter electromotive force has a high sine degree.

\section{STRUCTURE PARAMETERS DESIGN OF PERMANENT MAGNET FAULT-TOLERANT MOTOR}

Because of the different structure, compared permanent magnet fault-tolerant motor with the traditional permanent magnet synchronous motor, there are many differences in terms of parameter design. In this section, we use a four-phase six-pole permanent magnet fault-tolerant motor as an example, and research the design of motor structure and electromagnetic parameters. The main performance parameters of this motor are as follows: rated power $P_{N}=1 K \mathrm{~W}$, rated voltage $U_{N}=36 \mathrm{~V}$, rated speed $n_{N}=1200 \mathrm{rpm}$, number of the stator $N_{s}=8$, rotor pole pairs $p=3$, number of phase $m=4$, rated efficiency $\eta_{N}=90 \%$, the rated power factor $\cos \psi_{N}=0.8$.

\section{A. Design of stator inner diameter and core length}

The main dimensions of the permanent magnet fault-tolerant motor are specified the inside diameter and the effective axial length of stator core which can be determined according to the need of maximum torque and dynamic response indication ${ }^{[10]}$. When the biggest electromagnetic torque of motor is $T_{e m \max }(\mathrm{Nm})$, then the relationship between main dimensions and electromagnetic loads is:

$$
T_{e m_{\max }}=\frac{\sqrt{2} \pi}{4} B_{\delta 1} L_{e f} D_{i 1}^{2} A \times 10^{-4}
$$

where $B_{\delta l}$ is the flux density of fundamental amplitude $(T), A$ is the stator electric load valid value $(A / C M)$.

Obtained the relationship between the main dimensions of motor and the electromagnetic loads according to formula (1):

$$
\begin{gathered}
D_{i 1}^{2} L_{e f}=\frac{2 \sqrt{2} T_{e m_{\max }} \times 10^{4}}{\pi B_{\delta 1} A} \\
A=\frac{m N I_{1} K_{d p}}{p \tau}
\end{gathered}
$$

where $m$ is the motor phase, $N$ is the winding turns, $I_{1}$ is the stator current, $p$ is the rotor pole pairs, $K_{d p}$ is the winding factor, $\tau$ is the motor pole pitch. Here we take power load $A=150 A / \mathrm{cm}$, the flux density of fundamental amplitude $B_{\delta 1}=0.8 T$.

Because the dynamic response performance index of a permanent magnet fault-tolerant motor mainly refers to the motor that under the effect of maximum electromagnetic torque $T_{\text {emmax }}$ can accelerate linearly from rest to turning speed $\omega_{b}$ during time of $t_{b}$, that is:

$$
T_{e m_{\max }}=\frac{J \Delta \omega}{p \Delta t}=\frac{J \omega_{b}}{p t_{b}}
$$

where $J$ is the rotor and load inertia $\left(\mathrm{kg} \mathrm{m}^{2}\right)$.

Therefore, according to formula (4) we can obtain the ratio of maximum electromagnetic torque to the moment of inertia is:

$$
\frac{T_{e m_{\max }}}{J}=\frac{\omega_{b}}{p t_{b}}
$$

The moment of inertia of the motor rotor can approach to:

$$
J=\frac{\pi}{2} \rho_{F e} L_{e f}\left(\frac{D_{i 1}}{2}\right)^{4} \times 10^{-7}
$$

where $\rho_{F e}$ is the mass density of the rotor material iron $\left(\mathrm{g} / \mathrm{cm}^{3}\right)$.

We take formula (1) and formula (6) into equation (5), can obtain the stator inner diameter $D_{i 1}(\mathrm{~cm})$ is:

$$
D_{i 1}=\sqrt{\frac{8 \sqrt{2} p t_{b} B_{\delta 1} A}{\omega_{b} \rho_{F e} \times 10^{-3}}}
$$

Then according to equation (2), we can obtain the effective axial length of the stator core $L_{e f}(\mathrm{~cm})$ is:

$$
L_{e f}=\frac{2 \sqrt{2} T_{e m_{\max }} \times 10^{4}}{D_{i 1}^{2} \pi B_{\delta 1} A}=\frac{10 T_{e m_{\max }} \omega_{b} \rho_{F e}}{4 \pi p t_{b} B_{\delta 1}^{2} A^{2}}
$$

\section{B. Design of groove parameters}

Fig .1 shows the block diagram of stator slots of permanent magnet fault-tolerant motor after straightening. From Fig .1, we can know that the parameters which need be calculated include: notch thickness $H_{s 0}$, slot width $B_{s 0}$, stator tooth width $B_{t}$ and stator tooth height $H_{s 2}$.

Firstly, according to the magnetic saturation constraint conditions of the stator teeth, we obtained the tooth height and the tooth width. Secondly, according to the design requirements of slot leakage inductance, we derived the notch height and width. Finally, in accordance with the requirements of internal winding current density of stator slot, we calculated the other parameters, like the width of the groove bottom $B_{s 2}$ and the width of the groove top $B_{s 1}$.

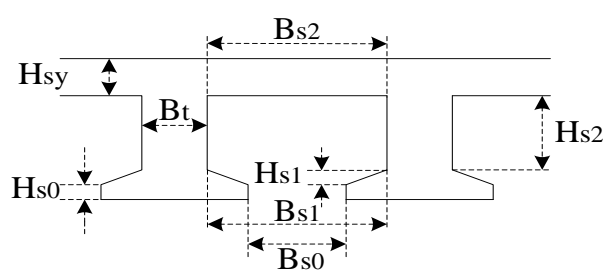

Figure 1. An alveolar structure of stator

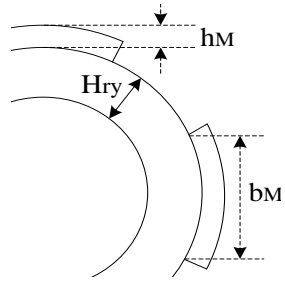

Figure 2. The rotor yoke structure 
1) Parameter calculation of stator teeth

Assuming all of the air-gap magnetic flux through the main stator teeth, so the stator tooth width is obtained as follows:

$$
B_{t}=\frac{B_{\delta} \cdot \alpha_{i} \tau}{b_{t_{\max }}}
$$

where $B_{\delta}$ is magnetic load, $\alpha_{i}$ is calculated pole arc coefficient.

Because when ferromagnetic material under normal circumstances, the maximum magnetic flux density of the stator teeth $b_{\text {tmax }}$ equal to $1.4 \sim 1.6 T$, therefore, this article selected $b_{\text {tmax }}=1.5 T$, and according to formula (9) can derive the stator tooth width $B_{t}$

Generally, the height and width ratio of the stator teeth is between 1.5 and 3. Because, if the ratio is small, the stator slot is very shallow, this may cause very high current density that through the inner winding. But if the ratio is large, then the stator slot is very deep, the stator yoke is easy to reach saturation, and the electromagnetic torque may reduce. So in this paper, we take the value of 2 , and the stator tooth height is:

$$
H_{s 2}=2 B_{t}
$$

\section{2) Calculation of notch parameter}

In order to reduce the saturation degree of the stator tooth tip maximum extent, at the same time to improve the slot leakage inductance $L_{s 0 \sigma}$, the notch thickness $H_{s 0}$ generally taken to be $(0.35 \sim 0.5) B_{t}$, this article is taken as 0.4 times, that is:

$$
H_{s 0}=0.4 B_{t}
$$

Slot leakage inductance $L_{s 0 \sigma}$ is:

$$
L_{s 0 \sigma}=\frac{2 \mu_{0} N^{2}\left(H_{s 0}+B_{s 0}\right)\left(L_{e f}+B_{s 0}\right)}{B_{s 0}}
$$

Because the notch width $B_{s 0}$ is much smaller than the effective axial length of stator core $L_{e f}$, therefore, formula (12) can be simplified as:

$$
L_{s 0 \sigma} \approx \frac{2 \mu_{0} N^{2}\left(H_{s 0}+B_{s 0}\right) L_{e f}}{B_{s 0}}
$$

Rearranging slot width $B_{s 0}$ is:

$$
B_{s 0}=\frac{2 \mu_{0} N^{2} H_{s 0} L_{e f}}{L_{s 0 \sigma}-2 \mu_{0} N^{2} L_{e f}}
$$

where the slot leakage inductance $L_{s 0 \delta}$ taken as 0.33 times of the coil inductance $L_{s}$, and has the following formulas:

$$
\begin{gathered}
L_{s}=\frac{E_{0}}{\omega_{e} I_{s}}=\frac{E_{0}}{2 \pi f_{e} I_{e}} \\
I_{e}=\frac{P_{N}}{m U_{N} \eta_{N} \cos \varphi_{N}}
\end{gathered}
$$

where $E_{0}$ is the motor back electromotive force $(V), \omega_{e}$ is the electrical angular frequency $(\mathrm{rad} / \mathrm{s}), \quad I_{s}$ is the steady-state short-circuit current $(A), I_{e}$ is the motor rated current $(A), f_{e}$ is the rated synchronization frequency $(\mathrm{Hz})$.
3) Calculation of armature winding turns and coil diameter

The definition of motor no-load back electromotive force(EMF) is:

$$
E_{0}=4.44 f_{e} N k_{w 1} \Phi_{0}
$$

where $f_{e}$ is the rated synchronization frequency $(H z), k_{w 1}$ is the winding factor, $\Phi_{0}$ is the fundamental magnetic flux air $\operatorname{gap}(W b)$, and has the following formulas:

$$
\Phi_{0}=\frac{2}{\pi} \cdot\left(\frac{4}{\pi} \sin \frac{\alpha_{i} \pi}{2} B_{\delta}\right) \cdot \tau L_{e f}
$$

So the number of turns of the armature winding $N$ is:

$$
N=\frac{0.18 E_{0} p}{f_{e} k_{w 1} B_{\delta} D_{i 1} L_{e f} \sin \left(\alpha_{i} \pi / 2\right)}
$$

According to the dimensions of slot form, we can get the area of stator slots $A_{s}$ is:

$$
A_{s}=\frac{\left(B_{s 1}+B_{s 2}\right) H_{s 2} \sin \theta}{2}
$$

where $\theta$ is the mechanical angle that relative to the centerline of the pole ( $\mathrm{rad})$, and:

Width of the top slot is:

$$
B_{s 1}=\frac{\pi\left(D_{i 1}+2 H_{s 0}\right)}{Q}-B_{t}
$$

Width of the bottom slot is:

$$
B_{s 2}=\frac{\left.\pi\left[D+\mathcal{X} H_{s 0}+H_{s 1}+H_{s 2}\right)\right]}{Q}-B_{t}
$$

where $Q$ is the number of stator slots, in order to reduce the degree of magnetic saturation of tooth boots, $H_{s 1}$ generally taken as $0.5 \sim 1 \mathrm{~mm}$.

4) Calculation of stator and rotor yoke portion thickness

The thickness of the yoke of stator and rotor needs to meet the constraints of magnetic saturation, for the four-phase six-pole permanent magnet fault-tolerant motor in this article, the maximum value of yoke flux density is 1.6 1.8T, which is slightly larger than the maximum limit value of flux density in tooth portion, in this paper the value is $1.6 T$. Then the thickness of the stator yoke portion $H_{s y}$ is:

$$
H_{s y}=\frac{1}{2} \frac{b_{\delta m} \alpha_{i} \tau}{b_{s y}}
$$

The thickness of the rotor yoke is:

$$
H_{r y}=\frac{1}{2} \frac{B_{\delta} \alpha_{p} \tau}{b_{r y}}
$$

where $b_{s y}$ is the flux density of stator yoke portion $(T)$, $b_{r y}$ is the flux density of rotor yoke portion $(T)$.

\section{Magnetic circuit design}

Magnetic circuit design includes the determination of overall structure, the determination of sizing and the selection of material, which focuses on the work of choosing permanent magnetic materials and designing the operating point. 


\section{1) Permanent magnet material selection}

In this paper, we chose $\mathrm{NdFeB} N 38 H$ as the permanent magnet material, the remanence density $B_{r 20}$ is $1.23 T$, the temperature coefficient $\alpha_{B r}$ is $0.12 \% /{ }^{\circ} \mathrm{C}$, the irreversible demagnetization loss $I L$ is $0.7 \%$, the calculated coercive force of permanent magnet $H_{c 20}$ is $899 \mathrm{kA} / \mathrm{m}$.

We can obtain following results according to the selection of $\mathrm{NdFeB} \mathrm{N} 38 \mathrm{H}$ :

(1)Remanent flux density during the operating temperature:

$$
\begin{aligned}
B_{r} & =\left[1+(t-20) \alpha_{B r} / 100\right] \times[1+I L / 100] B_{r 20} \\
& =1.18 T
\end{aligned}
$$

(2)Calculated coercive force during the operating temperature:

$$
\begin{aligned}
H_{c} & =\left[1+(t-20) \alpha_{B r} / 100\right] \times[1+I L / 100] H_{c 20} \\
& =833.7 \mathrm{kA} / \mathrm{m}
\end{aligned}
$$

(3)Relative permeability of the permanent magnet:

$$
\mu_{r}=\frac{B_{r 20}}{\mu_{0} H_{c 20} \times 1000}=1.089
$$

where $\mu_{0}$ is vacuum permeability, $\mu_{0}=4 \pi \times 10^{-7} \mathrm{H} / \mathrm{m}$.

2) Determine the shape of permanent magnet

Surface magnetic pole structure can improve the ability of isolation between the windings, in this article we use the surface-type tile-shaped magnetic poles in the permanent magnet fault tolerant motor, shown in Fig .3. The structure of permanent magnet contacting the air gap directly is easy processing and installation. And uses a concentric tile-shaped magnetic poles, i.e., the outer diameter and the inter diameter of the permanent magnets have a common center, it shown as in the Fig .4.

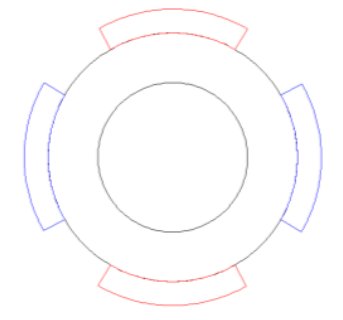

Figure 3. Surface tiles pole

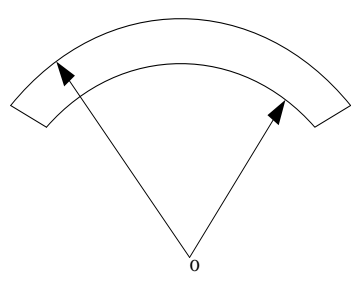

Figure 4. Concentric magnetic tiles

\section{3) Calculate the size of permanent magnet}

The main size parameters of permanent magnet part include the thickness and the width of permanent magnet, and can be determined by the following formula:

The thickness of permanent magnet $h_{M}$ is:

$$
h_{M}=\frac{\mu_{r}}{\frac{B_{r}}{B_{\delta}}-1} \delta_{i}
$$

The width of permanent magnet $b_{M}$ is:

$$
b_{M}=\alpha_{p} \tau
$$

where $\mu_{r}$ is the relative permeability of ferromagnetic material; $\delta_{i}$ is the calculating air gap length of $\operatorname{motor}(\mathrm{cm})$; $B_{r}$ is the residual magnetic induction intensity of permanent magnet $(T) ; B_{\delta}$ is the magnetic load $(T) ; \alpha_{p}$ is the percentage of pole embrace. Generally $B_{r} / B_{\delta}$ equal to $1.1 \sim 1.35$.

4) Permanent magnet magnetization way of design

In this paper, the arrangement of permanent magnet is in the way of Halbach array ${ }^{[11]}$, this kind of arrangement can not only enhance the air gap flux of motor, but also can weaken the magnetic flux of rotor yoke, which is particularly suitable for the rotor structure of using surface-mounted permanent magnet. Halbach array is a novel magnetic structure array that combines radial array with tangential array, as Fig .5(a) shows, so that we can make the magnetic field in one side of permanent magnet strengthening and the other side weakening. The rational design of Halbach array can make the air-gap flux density and the no-load back electromotive force having good sinusoidal.

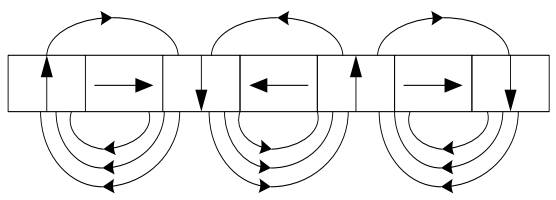

(a) Halbach array structure diagram

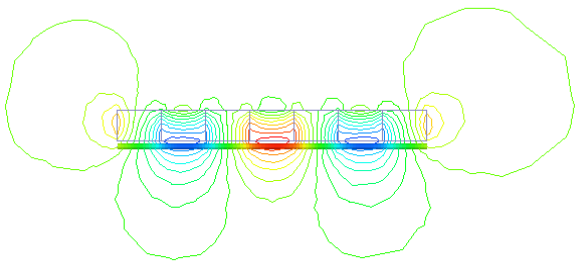

(b) The distribution of magnetic force lines

Figure 5. Magnetic field distribution of Halbach array structure

Fig .5 (b) shows the distribution of magnetic equipotential line of the permanent magnet motor with Halbach array which is calculated by the ANOSOFT which is one of the finite element analysis software. As we can see, after using Halbach array, the magnetic flux of rotor yoke significantly reduced, while the magnetic flux that across air gap into the stator significantly increased, which increases the magnetic load of permanent magnet motor and the density of force and energy, so Halbach array is very suitable for the ideal for the permanent magnet fault-tolerant motor with the inter rotor structure of permanent magnet posted outside. 
TABLE I . PARAMETERS OF 1KW Four-PhASE SiX-POLE

PeRmanent Magnet FAult-Tolerant Motor

\begin{tabular}{c|c|c|c}
\hline Rated voltage/ $V$ & 36 & Rated speed/r.min $^{-1}$ & 1200 \\
\hline Magnet Material & $\begin{array}{c}\mathrm{NdFe} \\
\mathrm{N} 38 \mathrm{H}\end{array}$ & $\begin{array}{c}\text { Stator and rotor } \\
\text { material }\end{array}$ & $\begin{array}{c}\text { DW310- } \\
35\end{array}$ \\
\hline $\begin{array}{c}\text { Outside stator } \\
\text { diameter/mm }\end{array}$ & 131.2 & $\begin{array}{c}\text { Inside stator } \\
\text { diameter } / \mathrm{mm}\end{array}$ & 65.6 \\
\hline $\begin{array}{c}\text { Stator tooth } \\
\text { width } / \mathrm{mm}\end{array}$ & 11.4 & Stator yoke thick $/ \mathrm{mm}$ & 5.4 \\
\hline $\begin{array}{c}\text { Inside rotor } \\
\text { diameter/mm }\end{array}$ & 64 & Rotor yoke thick/mm & 11.5 \\
\hline $\begin{array}{c}\text { Magnet thickness } / \mathrm{mm} \\
\text { Notch thickness } / \mathrm{mm}\end{array}$ & 8.7 & Stator core length $/ \mathrm{mm}$ & 139.3 \\
\hline Gap length $/ \mathrm{mm}$ & 0.8 & $\begin{array}{r}\text { Percentage of pole } \\
\text { embrace }\end{array}$ & 0.64 \\
\hline
\end{tabular}

Through the simulation of ANSOFT software, we determined to use the Halbach array with two pieces of permanent magnet per pole, and the radian numbers of these two pieces of permanent magnet are $35^{\circ}$ and $25^{\circ}$. Because we can get the highest sinusoidal waveform of no-load back electromotive force with this radian. According to the design results of this motor, we got the parameters of this $1 K W$ four-phase six-pole structure permanent magnet fault-tolerant motor that listed in Table 1 .

\section{EXPERIMENTAL TESTING OF THIS MOTOR}

Based on the permanents of motor size that designed before, We manufactured a $1 K \mathrm{~W}$ experimental prototype of this four-phase six-pole permanent magnet fault-tolerant motor. The external appearance is shown in Fig .6.

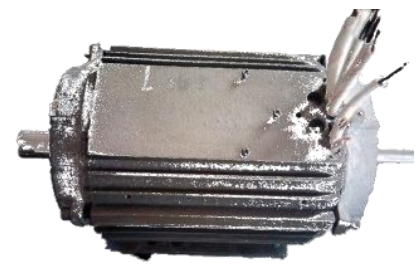

(a) External appearance of motor

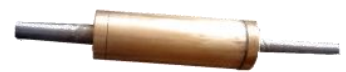

(b) Rotor of motor

Figure 6. A $1 \mathrm{KW}$ four-phase six-pole permanent magnet fault-tolerant motor
Fig .7 is an actual measured waveform of one phase no-load back electromotive force. From this figure, we can know that the sinusoidal of this waveform displayed very well, so the motor design is reasonably and accurate which laid a good foundation for the control research of fault-tolerant motor.

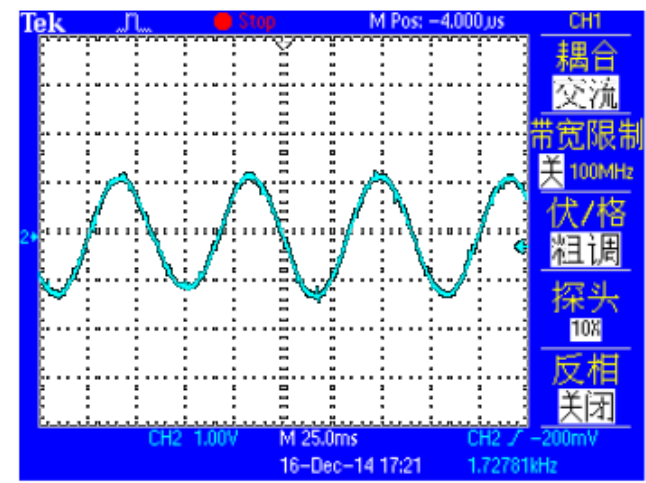

Figure 7. One phase no-load back electromotive force waveform

\section{CONCLUSION}

In this paper, for the requirement of power-driven applications with high-reliability, we have researched and designed one kind of permanent magnet motor of four-phase six-pole structure with Halbach array. Based on the characteristics of the motor structure and the analysis of fault-tolerant mechanism, and combined with the principles of electromagnetism and design method of Halbach array, we calculated the main dimensions and the electromagnetic parameters of the $1 \mathrm{KW}$ permanent magnet fault-tolerant motor. And through the experimental testing of this motor, we also verified the correctness and rationality of this motor design process.

\section{ACKNOWLEDGMENT}

The present paper has been financed by the National Natural Science Foundation of China (61004053, 61273151), Natural Science Foundation of Jiangsu Province (BK20141238), Qing Lan Project of Jiangsu Province, and Postgraduate Research Innovation Program of Jiangsu Province(CXLX13_681).

\section{REFERENCES}

[1] R. R. Errabelli , P. Mutschler. A fault tolerant digital controller for power electronic applications[C]. 13th Europe Conference on Power Electron Applications, 2009: 1-10.

[2] Niu Xuemei, Gao Guoqin, Liu Xinjun,et al. Dynamics modeling and experiments of 3-DOF parallel mechanism with actuation redundancy[J]. Transactions of the Chinese Society of Agricultural Engineering, 2013,29(16):31-41.

[3] A.M. El-Refaie. Fault-tolerant permanent magnet machines: a review[J]. IET Electronics Power Applications, 2011,5(1):59-74.

[4] Ji Jinghua, Sun Yukun, Zhu Jihong, et al. Design, analysis and experimental validation of a modular permanent-magnet machine $[\mathrm{J}]$. Transaction of China Electrotechnical Society, 2010,25(2): 22-29.

[5] B. C. Mecrow, A. G. Jack. Design and testing of a four-phase fault-tolerant permanent-magnet machine for an engine fuel pump[J]. IEEE Transactions on Energy Conversion, 2004, 19(2): 132 - 137.

[6] Hao Z Y, Hu Y W. Design and experimental analysis on the control system of high reliability fault tolerant permanent magnet motor 
used in electric actuator $[\mathrm{J}]$. Acta Aeronautica Et Astronautica Sinica, 2013, 34(1): 141-152.

[7] M. T. Abolhassani, H. A. Toliyat. Fault tolerant permanent magnet motor drives for electric vehicles[C]. IEEE International Electric Machines and Drives Conference, 2009:1146-1152.

[8] Hao Zhenyang, Hu Yuwen, Huang Wenxin, et al. Optimal current direct control strategy for fault tolerant permanent magnet motor[J]. Proceedings of the CSEE, 2011, 31(6): 46-51.
[9] Si Binqiang, Ji Jinghua, Zhu Jihong, et al. Two fault tolerant strategies for four-phase permanent-magnet fault tolerant machine [J]. Control and Decision, 2013,28(7):1007-1012.

[10] Tang Renyuan. Modern Permanent Magnet Machines-Theory and Design[M]. Beijing: Machinery Industry Press, 1997: 176.

[11] Zhu Deming, Yan Yangguang. Features of Air-Gap Flux Density in Segmented Halbach Permanent Magnet Synchronous Motor and Its No-Load EMF Waveform Optimization[J]. Transactions of China Electrotechnical Society, 2008, 23(11):22-26. 